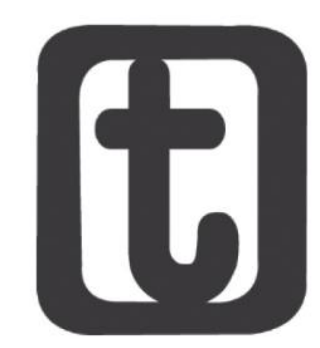

\title{
SUSPENSÃO OU MORTE: NOTAS SOBRE O COTIDIANO DA CLASSE QUE VIVE DE SEU TRABALHO
}

\author{
Suspension or death: considerations about the daily life of the social class that \\ makes a living out of their work
}

\author{
Robson de Oliveira* \\ https://orcid.org/0000-0003-3271-4086
}

\section{RESUMO}

O objetivo desse artigo é apresentar um conjunto de reflexões sobre o cotidiano a partir da condição humano-genérico por meio de elementos incontornáveis a sua consecução, tais como a heterogeneidade, a imediaticidade e a superficialidade extensiva. Ressalta ainda a suspensão do cotidiano por via do trabalho, arte, ciência e moral como forma de empreender o desenvolvimento humano-genérico e a práxis social. Por fim, o texto defende a necessidade de rompimento com os processos de reificação e alienação prementes à vida cotidiana, com foco nos processos de trabalho dos assistentes sociais, como meio de empreender gestas revolucionárias que rompam com as relações de exploração do modo de produção capitalista.

\section{PALAVRAS-CHAVE}

Vida Cotidiana. Cotidiano. Reificação. Alienação.

\section{ABSTRACTS}

This article's goal is to introduce a set of reflections on the daily life as from the human generic condition through the identification of unavoidable elements in its achievement, such as the heterogeneity, immediacy and extensive superficiality. The article also highlights the suspension of the daily life through work, art, science and moral as a way of undertake the human generic development and the social praxis. Lastly, the text defends the necessity of rupture with the rectification process and alienation crucial to the everyday life, focusing on the work process of social workers, as a way of undertaking revolutionary gestures that break with the relationship of exploration existing in the capitalist production mode.

\section{KEYWORDS}

Daily Life. Everyday. Rectification. Alienation.

\footnotetext{
* Assistente Social. Doutor em Serviço Social. Professor do curso de Serviço Social da Universidade Federal do Paraná - Setor Litoral. Rua Jaguariaíva, Tv. Caiobá, 512, Matinhos (PR), CEP.: 83260-000. Email: robson.de.oliveira@ufpr.br.
}

DOI 10.22422/temporalis.2021v21n41p367-380

\section{(cc) $\mathrm{EY}$}

(c) A(s) Autora(s)/O(s) Autor(es). 2019 Acesso Aberto Esta obra está licenciada sob os termos da Licença Creative Commons Atribuição 4.0 Internacional (https://creativecommons.org/licenses/by/4.o/deed.pt_BR), que permite copiar e redistribuir o material em qualquer suporte ou formato, bem como adaptar, transformar e criar a partir deste material para qualquer fim, mesmo que comercial. O licenciante não pode revogar estes direitos desde que você respeite os termos da licença. 


\section{tempor Olilis ouvera, rooson}

Submetido em: 6/4/2020.

Aceito em: 16/6/2021.

\section{INTRODUÇÃO}

$\mathrm{H}$

á um livro de José Saramago (2000) chamado A Caverna no qual o autor português narra a gradativa transformação do cotidiano de um trabalhador artesanal - o Sr. Cipriano - que, antes orientado pela luz solar e intempéries da natureza, conseguindo conciliar sua produção artesanal de louças de barro com os ritmos da natureza, se vê subitamente expropriado dos meios para a comercialização de seu trabalho. Essas mercadorias, que antes eram destinadas ao Centro, um empreendimento gigantesco que combina comércio, serviços e moradias, já não tem interesse no fruto de seu trabalho. Todavia, tudo o que pode ser vendido precisa ser ofertado no Centro, caso contrário, não possui valor de uso. O Centro é o monopólio e o vocalizador do que é ou não consumível. Seu trabalho e sua rotina de anos a fio são, contra sua vontade, alteradas.

A primeira reação do Sr. Cipriano é a descrença, o não entendimento do quê mudou tão radicalmente no Centro para que suas louças passassem a ser recusadas. Elas ainda tinham a mesma forma, durabilidade e função. "É a cadeia produtiva", diz um gerente, "agora os produtos virão do Oriente". O Sr. Cipriano precisará repensar o quê produzir e que tipo de mercadoria ofertar: tem-se aqui o início do que podemos denominar de suspensão do cotidiano para essa personagem.

Mais do que a busca pela escapatória do Sr. Cipriano desse pesadelo de tintas kafkanianas narrada por Saramago, esse artigo irá se debruçar sobre o cotidiano. Nos deteremos sobre a forma como o cotidiano é apresentado por certos intelectuais da teoria social crítica, como esse se estrutura e se organiza no ordenamento da vida social e, mais que isso, na forma como o cotidiano reflete e surte efeitos diretos sobre a classe trabalhadora, culminando na possibilidade de estratégias que permitam romper com certas condutas que afetam a genericidade humana.

Precauções metodológicas são requeridas aqui. Seria uma tarefa hercúlea realizar um recorte da categoria cotidiano na extensa tradição de pensadores da teoria social crítica que elaboraram teses que ampliam, recuperam e atualizam os esforços de decifrar essa manifestação da vida humana. Na verdade, incorreríamos, muito provavelmente, na mutilação de categorias que, quando trabalhadas isoladamente, tendem a ruir por terra o arsenal heurístico composto por intelectuais da tradição marxista, como Lukács e Heller, por exemplo. Nessa tradição, não há uma teoria do cotidiano, ou melhor, da vida cotidiana que rigorosamente não esteja agregada à reificação, ideologia e alienação. Essas, por sua vez, caso careçam dos pilares fundamentais da obra de Marx (método dialético, perspectiva da revolução e teoria do valor trabalho), incorrem no inevitável esquartejamento desse arsenal.

Dessa forma, esse artigo representa um esforço na tentativa de elaborar algumas indicações a partir de Lukács e Heller sobre a vida cotidiana, principalmente em um capítulo de Ontologia Dell'Essere Social e de autores que em seu lastro (Netto e 


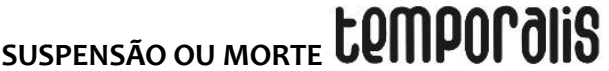

Falcão) se debruçaram sobre essa temática, sabendo de antemão que não se esgotará aqui a premência em torno desse debate.

\section{VIDA COTIDIANA: BREVES INDICAÇÕES}

Como aponta Löwy (1987) no prefácio da obra assinada por Netto e Falcão (1987), Lukács em História e Consciência de Classe identifica na reificação presente nas relações entre os indivíduos ${ }^{1}$ o típico do cotidiano, o que tornaria o rompimento com a reificação da vida cotidiana presente no sistema capitalista parte da práxis revolucionária e ação emancipadora da classe oprimida. No capítulo "L'estraniazione" da obra "Ontologia Dell’Essere Sociale", Lukács aborda os aspectos ontológicos da alienação a partir de uma rigorosa leitura marxiana que se debruçará sobre a religião problematizando a alienação e a reificação para apresentar as possíveis formas de superação desses fenômenos. Ainda que a religião seja abordada pelo marxista húngaro, ele reconhece em seu argumento, que os processos de reificação não podem ser restritos à esfera religiosa pois, "[...] a circulação das mercadorias, a economia capitalista, a sucessiva manipulação dela derivada, os seus respectivos reflexos ideológicos produzem todo dia e toda hora reificações em massa"" (LUKACS, 1976, p. 110).

Esse capítulo, além de desenvolver uma densa discussão sobre a reificação, apresenta uma análise profunda a respeito do cotidiano e vida cotidiana através da tríade reificação, alienação e ideologia. O que Lukács irá chamar de ontologia da vida cotidiana:

[...] a alienação de cada indivíduo se desenvolve pelas suas interações com a própria vida cotidiana. Ela é, no seu conjunto, e nos aspectos particulares, um produto das relações econômicas dominantes e, obviamente, são estas que exercem os influxos em última análise decisivos sobre os homens, também na esfera ideológica. Isto não entra em contradição com o fato de que o médium entre a estrutura econômica geral da sociedade e o indivíduo seja justamente o ser da vida cotidiana, o qual, ao contrário, dá consistência aos conteúdos e às formas daquele momento (LUKÁCS, 1976, p. 64).

A tese central dessa discussão é a necessária relação imediata entre teoria e prática compreendida como um aspecto fundamental da vida cotidiana. Essa relação é

\footnotetext{
1 O termo indivíduo comparecerá ao longo do texto na acepção apresentada por Marx (1978, p. 10): "O indivíduo é o ser social. A exteriorização da sua vida - ainda que não apareça na forma imediata de uma exteriorização de vida coletiva, cumprida em união e ao mesmo tempo com outros - é, pois, uma exteriorização e confirmação da vida social. A vida individual e a vida genérica do homem não são distintas por mais que, necessariamente, o modo de existência da vida individual seja um modo mais particular ou mais geral da vida genérica, ou quanto mais a vida genérica seja uma vida individual mais particular ou geral."

2 Sobre a religião e a vida cotidiana escreve Lukács: “[...] desde o início - e em muitos casos até muito depois - é um sistema para regular por completo a vida da sociedade; sobretudo satisfaz a necessidade social de regular a vida cotidiana dos homens, de uma forma tal de ser capaz de exercer de uma maneira ou de outra um influxo direto sobre a conduta de vida de todos os indivíduos em questão" (LUKÁCS, 1976, p. 80).
} 
explicitada em uma análise esmiuçada a partir da superação da reificação que, embora tenha em si caráter ideológico, apresenta-se aos homens e mulheres como modos de ser, o que a revela como um meio ideológico.

\begin{abstract}
Na vida cotidiana, devido à conexão imediata entre teoria e práxis, são possíveis dois diferentes tipos de função das ideologias: ou elas operam puramente como ideologias, um dever-ser que dá direção e forma às decisões do homem singular na vida cotidiana ou a concepção de ser que nelas está contida aparece aos homens da vida cotidiana como o próprio ser, como aquela realidade frente a qual somente reagindo adequadamente eles são capazes de organizar a sua vida de conformidade com as próprias aspirações. Esta bipartição está sem dúvida alguma presente nos estádios mais avançados do desenvolvimento social. (LUKÁCS, 1976, p. 116).
\end{abstract}

É no que Marx (2013) designou como metabolismo entre sociedade e natureza que se abriga a formulação específica para a identificação das determinações da prática da transformação, reflexão teórica e estética. E, para Lukács (1976), é na objetividade heteróclita da vida cotidiana que estão os componentes produzidos pelas distintas esferas reproduzidas e reelaboradas em sua legitimidade específica (arte, trabalho, ciência).

Duas categorias de análise essenciais à elucidação da vida cotidiana e do cotidiano são a totalidade e a mediação. A totalidade, compreendida a partir de Lukács (2003) como um complexo de complexos, é uma categoria fundamental da realidade. A outra é a mediação, necessária para abarcar a complexidade da estrutura da realidade como totalidade concreta sem anular, no processo, a categoria da negação.

A totalidade sem mediação é inerte: as contradições - a negatividade que a permeia e responde pelo devir - não se desenvolveriam em encadeamentos e séries determinadas e determinantes, nem apresentariam caráter de necessidade. A mediação, por seu turno, só existe nos e entre os complexos constituintes da totalidade e carece de efetividade fora da sua dialética imanente (LUKÁCS, 1976, p. 81).

Por meio das indicações de Lukács presentes no capítulo já mencionado de Ontologia dell'essere sociale, Netto (1987), identifica as determinações fundamentais da cotidianidade:

Heterogeneidade - que seria o local onde a vida cotidiana configura a heterogeneidade que lhe é imanente. É colocada em processo por via da interseção das atividades que compõem o conjunto das objetivações do ser social. Necessário ressaltar ainda o caráter heteróclito onde, simultaneamente, se movimentam fenômenos e processos de natureza compósita (linguagem, trabalho, interação, jogo, vida política e vida privada, etc.); Imediaticidade - que expressa o modo como os homens atuam na vida cotidiana. Esta ação para ser considerada como imediaticidade requisita uma resposta ativa ao padrão de comportamento próprio da cotidianidade. Em síntese, trata-se da relação direta entre pensamento e ação em que a conduta específica da cotidianidade, sem essa a conduta imediata não estaria encharcada por automatismos e o espontaneísmo, estes centrais à reprodução do indivíduo enquanto tal 


\section{suspensio ou morre Eempordilis}

seriam inviáveis; Superficialidade Extensiva - em que vida a cotidiana mobiliza em cada homem certa atenção e força para adequar-se à sua heterogeneidade e imediaticidade. Para isso o indivíduo deve responder levando em conta o somatório dos fenômenos que comparecem em cada situação precisa, sem considerar as relações que os vinculam de forma desatrelada ou desistoricizada de suas raízes históricas, econômicas e culturais (NETTO, 1987, p. 66 grifo nosso).

Todo indivíduo e sociedade possuem vida cotidiana, sendo essa insuprimível e ineliminável no que tange à constituição, produção e reprodução do ser social. Nela não há, a partir de Lukács (1976), exterioridade meta-histórica, mas reconhecimento dos diferentes estágios de produção material da sociedade.

Ou seja, cada época histórica possui uma vida cotidiana distinta. Essa diferença, todavia, não é apenas histórica, já que em um mesmo período indivíduos podem possuir cotidianos distintos ditados pelas diferenças entre os grupos ou classes sociais. O desenvolvimento das forças produtivas é um dos principais fatores delimitadores dessa distinção entre épocas e classes. Além da diferenciação entre cada época histórica e entre cada grupo social, é importante ressaltar que sendo o cotidiano um dos níveis constitutivos da história, nele se localiza a reprodução social através da reprodução dos indivíduos.

\section{TRAÇOS E CARACTERÍSTICAS DA VIDA COTIDIANA}

Esse item irá apresentar brevemente os estudos de autores influenciados por Lukács que apresentam contribuições sobre a vida cotidiana e indicações dessa relação com os escritos marxianos e lukacsianos nessa temática.

Sucintamente, pode-se afirmar que a finalidade do pensamento gestado no cotidiano é concretizar atividades inerentes a esse, o que resulta em unidade de pensamento e ação. Todavia, não se trata de práxis e não há uma relação entre essa ação e a teoria. A práxis só ocorre quando se trata de atividade humano-genérica consciente, isto é, "[...] na cotidianidade, a atividade individual não é mais do que uma parte da práxis, da ação total da humanidade que, construindo a partir do dado, produz algo novo, sem com isso transformar em novo o já dado." (HELLER, 1989, p. 32).

Heller (1989) afirma que a alienação, enquanto um dos componentes da vida, impregna-se nas possibilidades concretas postas ao desenvolvimento genérico da humanidade - definição próxima a de Marx (1978), na qual alienação é tudo aquilo que mutila e impede o desenvolvimento da essência humana. A vida cotidiana possui afinidade com a alienação, o que acaba por gerar um abismo entre 0 desenvolvimento humano-genérico e as possibilidades de desenvolvimento dos indivíduos e, ainda, entre a produção humano-genérica e a participação consciente do indivíduo nessa produção. Em síntese, a vida cotidiana não é alienada por sua estrutura, mas por determinadas circunstâncias sociais.

[...] o moderno desenvolvimento capitalista exacerbou ao extremo essa contradição. Por isso, a estrutura da cotidianidade alienada começou a expandir-se e a penetrar em esferas onde não é necessária, nem constitui 
uma condição prévia da orientação, mas nas quais aparece até mesmo como obstáculo para essa última (HELLER, 1989, p. 39).

A ultrageneralização, pragmatismo, juízos de valor, dentre outros, podem ser considerados como circunstâncias que obnubilam uma apreensão global da realidade já que a prática social exige a manipulação de variáveis na maior parte das vezes imediatas. Já em outros casos, quando as circunstâncias possibilitam um espaço de tempo para a reflexão, encaram-se barreiras praticamente instransponíveis de natureza econômico-sociais (LUKÁCS, 1976).

As respostas funcionais requisitadas aos indivíduos exigem o exercício dessa manipulação de variáveis para a obtenção de resultados "[...] o que conta não é a reprodução veraz do processo que leva a um desfecho pretendido, porém o desfecho em si; no plano da cotidianidade, o critério da utilidade confunde-se com o da verdade" (NETTO, 1987, p. 67).

Na cotidianidade é impossível acessar o todo da realidade, o conhecimento acaba por se restringir ao aspecto inerente à atividade, ou seja, o pragmatismo do pensamento cotidiano traz a reboque a fé e confiança. Como Heller (1989) esclarece, há distinções entre essas, sendo que a confiança é "[...] afeto do indivíduo inteiro [...]" (1989, p. 34) e a fé é oriunda sempre do individual-particular, "[...] não há lugar para a fé quando está em jogo a 'justeza' da manipulação ou da objetivação coisificada; em princípio, basta a experiência para realizar as correções necessárias" (HELLER, 1989, p. 34).

Para Heller, o homem da cotidianidade só é capaz de levar sua vida adiante pelo contato constante com outros indivíduos, ainda que o conhecimentos dos homens previsão do seu imediato agir futuro - nunca se eleva ou se constitui como um saber real. Para Lukács (1976), a imediaticidade da vida cotidiana “[...] está sempre envolta por um limite de ignorância que é impossível padronizar completamente” (LUKÁCS, 1976, p. 84).

Essa imediaticidade é o espaço onde se desenvolve o pragmatismo e rotina. Todavia, ao invés de restringir a cotidianidade ao nicho da empiria e reprodução da "rotina" ou como excluída da história, é imprescindível compreendê-la no cerne do evolver histórico. É na vida cotidiana que transcorre a vida do indivíduo - esse como ser particular e genérico - que agrega em si toda a constituição e essência da humanidade. Não é possível a noção de indivíduo sem essa dupla constituição genérico e individual, o que requisita, justamente, o desenvolvimento de uma sociedade em que essas partes constituintes da ontologia do ser social coexistam sem mutilação.

A complexidade dessa relação individual-genérico requisita elencar algumas de suas características. Uma delas é a ultrageneralização acessível no pensamento e comportamento cotidiano por meio de estereótipos, analogias e esquemas previamente elaborados que nos são impingidos, segundo Heller (1989), pela influência do meio em que crescemos e vivemos. Numa primeira aproximação, 


\section{suspensio ou morre Eempordilis}

poderíamos identificar na tradição um dos principais alfobres das ultrageneralizações. Não sendo exclusiva da tradição, a ultrageneralização pode se apoiar na experiência pessoal sem ignorar que a própria contraposição ao modelo a ser superado pode possuir outras ultrageneralizações compatíveis ao sistema do qual se opõe.

Outra característica da vida cotidiana é o precedente, o apoio no conhecimento da situação em referência a acontecimento pregresso. Trata-se, para Heller (1989), de um indicador útil para a forma como devemos nos comportar e agir ainda que tenha "[...] efeitos negativos, ou mesmo destrutivos, apenas quando nossa percepção do precedente nos impede de captar o novo, irrepetível e único de uma situação" (HELLER, 1989, p. 36). Há ainda a imitação, a qual ocorre pela assimilação do sistema consuetudinário, o problema formado aí é saber se "[...] somos capazes de produzir um campo de liberdade individual de movimentos no interior da mimese ou, em caso extremo, de deixar de lado completamente os costumes miméticos e configurar novas atitudes" (HELLER, 1989, p. 36).

A entonação refere-se à configuração de nossas atividades e ações e na modulação de como os outros entendem nossas condutas. Os sujeitos fornecem o cariz "tonal" de certos meios e alguém que não produza entonação - ou que não a perceba torna-se insensível a esse fenômeno na compreensão das relações sociais. Já a espontaneidade seria a característica dominante da vida cotidiana, ainda que existam graus distintos de espontaneidade, sendo essa uma tendência no exercício das ações caracterizando tanto as motivações particulares quanto as atividades humanogenéricas (HELLER, 1989).

Existe ainda a probabilidade no exercício da vida cotidiana, já que certas condutas dispensam o cálculo e medições científicas das consequências de certas ações para obter uma suposta exatidão, seja pelo funcionamento do conjunto de elementos inanimados que possibilitam a ação ou pela forma como os demais indivíduos podem se portar no momento. Acessar um elevador não requisita do usuário o cálculo da distância do solo até o andar, a velocidade do elevador no trajeto, a possibilidade desse trajeto ser interrompido pela utilização por outro morador ou o percentual de freios de emergência que tenham falhado sobre responsabilidade da empresa de manutenção no último ano. Quando opto por utilizar esse meio de deslocamento vertical, o que preciso saber é o andar aonde devo chegar. As probabilidades do que possa vir a ocorrer são inúmeras e pouquíssimas vezes são incluídas na decisão sobre o uso ou não desse meio.

Em suma, a obrigação de realizar diversas atividades em um breve período de tempo acaba por agregar em nossas ações essas características da vida cotidiana sem que seja necessário, ao mesmo tempo, superá-las visando a reflexão das inúmeras possibilidades postas, o possível aí é ignorá-las ainda que conscientes de sua existência. 


\title{
temporolilis ouvera, rosson
}

Todas essas características possuem como similitude a finalidade que expressam, objetivando que os indivíduos vivam seu cotidiano. Dessa maneira, conclui Heller (1989), não há vida cotidiana sem essas características.

Essa compreensão aproxima o cotidiano da empiria, o que significa que na cotidianidade pode-se apelar a um tipo de racionalidade apoiado na intuição do que o cotidiano nos oferta, já que não se requisita para certas ações a detenção de um conhecimento caucionado na segurança científica, mas no pragmatismo da ação requisitada e necessária.

\section{A SUSPENSÃO DO COTIDIANO}

Para Heller (1989), existem quatro formas de suspensão da vida cotidiana que possibilitam a passagem do singular ao humano genérico: o trabalho, a arte, a ciência e a moral. A singularidade se constitui como parte da universalidade, o que leva o indivíduo a sentir-se partícipe com os outros indivíduos e a realidade. Haveria, por isso, cinco atributos que definem a essência humana em sua possibilidade de suspensão do cotidiano: o trabalho, a sociabilidade, a universalidade, a consciência e a liberdade. Esses se encontram como potências a serem desenvolvidas.

Se a vida cotidiana é intrínseca a todo indivíduo, não há identificação com a atividade humano-genérica que não esteja alojada, com graus distintos de suspensão ou absorção dessas pelo cotidiano. Isso que compreendemos como "vida cotidiana" possui em seu cerne a heterogeneidade, constituindo partes que vão da organização do trabalho, vida privada até os lazeres.

\begin{abstract}
A heterogeneidade e a ordem hierárquica (que é condição da organicidade) da vida cotidiana coincidem no sentido de possibilitar uma explicitação 'normal' da produção e da reprodução, não apenas no 'campo da produção' em sentido estrito, mas também no que se refere às formas de intercâmbio. A heterogeneidade é imprescindível para conseguir essa 'explicação normal' da cotidianidade; e esse funcionamento rotineiro da hierarquia espontânea é igualmente necessário para que as esferas heterogêneas se mantenham em movimento simultâneo (HELLER, 1989, p. 18).
\end{abstract}

As necessidades humanas que ganham consecução a partir do "Eu" constituem a dinâmica da particularidade individual humana. "Sob esse aspecto, não há diferença no fato de que um determinado "Eu" identifique em si ou conscientemente com a representação dada do genericamente humano, além de serem também indiferentes os conteúdos das necessidades do "Eu" (HELLER, 1989, p. 20). O indivíduo ainda que ser genérico jamais o é isoladamente.

O desenvolvimento desse indivíduo necessita que se considere suas condições de possibilidades para o exercício da liberdade oriundas da cotidianidade. Essa interrupção da vida cotidiana não é uma constante, mas tende a compor um circuito de elevação e retorno. E é em seu retorno que o indivíduo age de forma mais eficiente e percebe a própria cotidianidade diferente, tendo nela um espaço compossível entre humano genérico e indivíduo. 


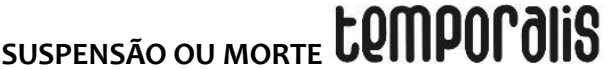

Para Netto, contém-se aí uma dialética de tensões: "o retorno à cotidianidade após uma suspensão (seja criativa, seja fruidora) supõe a alternativa de um indivíduo mais refinado, educado (justamente porque se alçou à consciência humano-genérica)" (NETTO, 1987, p. 69). Nesse retorno à vida cotidiana, por essa experiência de suspensão prévia, o indivíduo regressa modificado por essa relação cotidianidade/suspensão que permite em sua processualidade o desenvolvimento e constituição do ser social.

\section{A VIDA COTIDIANA E O PROCESSO REVOLUCIONÁRIO: ALGUMAS INDICAÇÕES PARA O SERVIÇO SOCIAL}

No romance de Saramago, a alternativa vislumbrada pelo Sr. Cipriano é a confecção de pequenas figuras que remetam em sua forma a profissões como médico, professor, costureira, pescador e agricultor com a intenção de reconquistar o valor de uso de suas mercadorias junto ao Centro. Uma encomenda é feita, mas a comercialização não tem sucesso causando prejuízo para o Sr. Cipriano e sua família. Essas figuras de barro, que tão bem remetem à condição do trabalhador, algo moldado da terra sob calor escaldante, que gradativamente ganha forma, mas que facilmente é descartada, destituída de função e por isso, destruída, é a mostra final ao Sr. Cipriano que sua relação com o trabalho e toda sua vida cotidiana nunca mais será a mesma.

A verdade é que sua elevação do cotidiano ocorreu quando passou a produzir figuras que remetiam a sua condição de trabalhador, aos homens e mulheres que conheceu ao longo de sua vida e que passaram a ser formados da sua argila como obras de arte, mas com a intenção de serem comercializadas como souvenirs. Agricultores, costureiras, pescadores, todos esses para o Centro nada mais eram do que utensílios comercializáveis, mas para o Sr. Cipriano eram a expressão de um trabalhador e artista que descobriu formas de converter seu cotidiano na busca por estratégias de sobrevivência. A recusa do Centro a isso, à elevação do cotidiano alcançado pelo Sr. Cipriano sem valor de uso para o comércio é, na obra de Saramago, um golpe duro demais para suas forças e, por extensão, a toda classe trabalhadora submetida a exploração do trabalho alienado.

Falcão (1987) define a vida cotidiana como um mundo de alienação, impregnado de banalidade e mediocridade. Nesse mundo, é necessário entender que o espaço privado de cada indivíduo é repleto de ambivalências, tragédias, anseios e frustrações em que habitam concomitantemente existências fictícias e reais, abstratas e concretas, heterogêneas e homogêneas organizadas em estruturas fragmentadas e hierárquicas. Reconhece assim a vida cotidiana como fonte de conhecimento e prática social e, a partir de Lefebvre, afirma que o Estado moderno conseguiu assegurar o papel de gestor da sociedade através da manutenção de um conjunto de condutas que possuem na cotidianidade sua pedra angular. O edifício político burocrático possui fissuras que precisam das atividades administrativo/burocráticas para sanarem essas falhas, eliminando qualquer possibilidade de liberdade 


\section{tempor Olili ouvera, rooson}

intersticial. Nesse processo, o que o indivíduo procuraria seria justamente uma forma de alargar e passar por essas fissuras.

Esse cotidiano, oriundo do modo de produção capitalista, possui como elemento central a contradição entre capital e trabalho, disso sabemos. A apropriação privada dos meios de produção por uma classe enquanto outra possui como única e mais valiosa mercadoria a venda de sua força de trabalho em troca de um salário, torna a produção, circulação e consumo das mercadorias partes organizadoras das relações sociais definidoras de nosso cotidiano. Mas aqui trata-se de "cotidianos" separados por classes sociais. Em síntese os cortes no âmbito do consumo e acesso a bens.

Nesse universo organizado por um cotidiano que recusa ou não oferta a elevação por parte de seus trabalhadores, entende-se que está sempre presente o risco de uma sublevação da classe revolucionária que detém em si as necessidades mais radicais de superação desse modo de produção, o qual é o feixe organizador do tipo de cotidiano que enfrentamos na condição humano-genérico e individual. Por isso, 0 cotidiano não é apenas rotina, metas, acordos, normas, imediaticidade. Na realidade, é por ele que se gesta as possibilidades de resistência, enfrentamentos e transformações.

Dentro desse compósito de controle e adestramento da classe trabalhadora em seu cotidiano estão as máquinas, smartphones, "bugigangas" e utensílios destinados a usos cotidianos e que no extremo permitem a manipulação dos sonhos de ascendência, atendendo a necessidades do estômago e da fantasia desse cotidiano reificado. Para Falcão (1987, p. 19), "a vida cotidiana é em si o espaço modelado (pelo Estado e pela produção capitalista) para erigir o homem em robô: um robô capaz de consumismo dócil e voraz, de eficiência".

É sua funcionalidade que chancela a validade do cotidiano, manifestando-se como uma característica que objetiva ser precisa, destinada aos homens e mulheres concretos.

\footnotetext{
Nenhuma existência individual cancela a cotidianidade. Daí que esta imponha aos indivíduos um padrão de comportamento que apresenta modos típicos de realização, assentados em características específicas que se cristalizam uma modalidade de ser do ser social no cotidiano, figurada especialmente num pensamento e numa prática peculiares. Ambos se expressam, liminarmente, num materialismo espontâneo e num tendencial pragmatismo. Os constrangimentos da dinâmica cotidiana exigem que os indivíduos respondam a eles sem pôr em causa a sua objetividade material. (NETTO, 1987, p. 67 grifos do autor).
}

A alienação se aloja na vida cotidiana, mas não na produção de gestas emancipatórias, à alienação interessa encontrar meios de caucionar a ordem. Não há, dessa forma, cidadãos e vínculos comunitários, mas uma massa alimentada pela fetichização, tornando o homem alienado de si e o pensador alienado de sua essência. 


\section{suspensáo ou morre Elmpordilis}

Ao que se refere o trabalho, esse não consegue ser uma atividade vital de cariz criador restringindo-se ao meio de sustento, ou seja, o trabalho alienado. Marx (2013) já afirmava que o homem produz a mercadoria e, o próprio homem como mercadoria ao ter o trabalho como algo alheio e externo, se aliena de si mesmo. A vida cotidiana requisita o "arsenal heurístico" marxista ao partir da crítica da economia política por via de "espaços" circunscritos no capitalismo, nos quais se pode exercitar a autonomia, sendo possível a retotalização humana que compensaria e reduziria os efeitos deletérios da vigente divisão social do trabalho.

A manutenção funcional do capitalismo tem na reificação das relações sociais seu caixilho principal, ofertado pela manutenção das relações de exploração e ordenamento social oriundas do cotidiano apresentadas de forma dispersa, quase em uma cartografia que escapa a uma centralização de sua ação em torno do Estado, governo, aparelho de repressão e economia.

\footnotetext{
E mais, fenômeno peculiaríssimo: a visibilidade do poder opressivo (outrora por exemplo, o capitalista) se esvaneceu - ele é tanto mais eficiente em suas manifestações econômicas, sociais, políticas e culturais quanto menos é localizável, mais funciona, menos é identificável. A ubiquidade deste poder, desta weberiana autoridade "racional" e sem rosto, se instala nos trilhos por onde escorre o cotidiano (porque, aqui, a vida é o cotidiano, esse produzir-se e reproduzir-se num eterno retorno, numa tautologia plena) [...] Está em todas as partes e não reside em lugar algum. Escamoteia os fluxos, as continuidades e as rupturas: dá ao viver a sequência da lanterna mágica - normas, trabalho, lazer, etc., tudo é uma mescla inorgânica cujo único enlace é a sucessão no tempo e no espaço: a vida é uma justaposição de objetos, substâncias, implementos. [...] A ubiquidade do poder - incorreto, gasoso e onipotente - esconde o poder na ubiquidade (NETTO, 1981, p. 83).
}

Na sociedade burguesa, falar em luta de classes e na dominação de uma classe sobre outra significa reconhecer que no âmbito do cotidiano se legitima uma opressão transvestida de administração.

\footnotetext{
Aqui, é o inteiro cotidiano dos indivíduos que tende a ser administrado, um difuso terrorismo psicossocial se destila pelos poros da vida e se instala em todas as manifestações anímicas e todas as instâncias que outrora o indivíduo podia reservar-se como áreas de autonomia (a constelação familiar, a organização doméstica, a fruição estética, o erotismo, a criação dos imaginários, a gratuidade do ócio, etc.) convertem-se em limbos programáveis como áreas de valorização potencial do capital monopolista (NETTO, 1981, p. 84).
}

Por estarem os indivíduos inseridos em uma sociedade onde suas existências são capitaneadas à uma instância alheia, expressa pela sacralização do institucionalizado e onde não encontram sentido ou razão no seu trabalho e resultado dele, torna-se imperativo assumir a vida cotidiana enquanto constitutivo do real e, a partir disso, reconstruir de maneira reflexiva a ontologia da totalidade concreta emanada da sociedade visando sua radical transformação. 


\section{tempor Olilis ouvera, rooson}

O tempo é ainda uma indicação valiosa de como se pode encaminhar a noção de vida cotidiana como componente constitutivo da história e fenômeno a ser superado em sua reificação e alienação. Pois que, além da força de trabalho que os trabalhadores trocam pela mercadoria dinheiro, há ainda o componente tempo. Já que o tempo no qual o operário exerce suas diversas funções é um tempo de sua vida, mas que não se expressa em sua vida, como já afirmará Marx, "Para ele (operário) quando terminam essas atividades é que começa a sua vida, à mesa, no boteco, na cama" (MARX, 1980, p. 18).

Nesses termos, o cotidiano é o trabalho; a vida é o resto que cabe no tempo que sobra. É como se o mais elementar e pernicioso da constituição do que é cotidiano seja o elemento combinatório perfeito ao formato das relações de trabalho no capitalismo. Embora se assevere que o operário é um homem livre para vender sua força de trabalho, como tratar a venda desse tempo que, como mercadoria, parece ser subsumida no processo? São horas de sua vida diária, onde sua cotidianidade pertence a quem a paga pela força de trabalho.

Para isso, a identificação das mediações é imprescindível para a ultrapassagem do que se oculta na cotidianidade evitando a naturalização dos fenômenos encharcados pelos processos de reificação e alienação, tornando visível a tensão presente no tecido social. Pois que o próprio rompimento com a vida cotidiana, como gestada sobre a reificação extremada, se apresenta como imprescindível para a práxis revolucionária.

A interrupção do cotidiano e a forma como se objetiva a partir dela a congruência de ações que visem o exercício de autonomia dos indivíduos merece atenção por parte de profissionais como os assistentes sociais. Não se trata da recusa do cotidiano como a antítese do processo revolucionário, mas da apreensão de que, em um momento revolucionário, essa expressão da vida social se encontraria completamente suspensa, onde até mesmo o indivíduo que gozasse das mais insipidas condições de desenvolver suas potencialidades no campo do real perceba que está vivendo, junto aos outros, um momento revolucionário e único na história. Essa característica de único não se generaliza, é única por agregar a comunhão entre os homens e mulheres, como sugerida por Heller (1989). Essa apreensão corrobora com a apresentada por Löwy (1989):

[...] a ação coletiva, a práxis libertadora, a transformação dos exploradores em sujeitos históricos conscientes. Esta ação não conduz evidentemente à negação da cotidianidade - categoria insuprimível da vida social como o constata com razão o último Lukács -, mas à sua suspensão durante o momento revolucionário, e, sobretudo, a mais longo prazo, à superação da natureza reificada das relações sociais cotidianas (LÖWY, 1989, p. 11-12).

Engels e Marx (2010) reconheciam um espectro que rondava a Europa por viverem em um momento revolucionário e, se admitimos que estamos hoje ainda em um momento de construção de uma nova ordem societária, logo como indivíduos em processo revolucionário, precisamos ter claro que um dos componentes a serem 


\section{suspensáo ou morre Elmpordilis}

apropriados e ultrapassados é a vida cotidiana como constituída atualmente em suas reificações extremadas.

\section{CONSIDERAÇÕES FINAIS}

O Centro - ao qual o Sr. Cipriano está submetido - é o local e condição na qual todo trabalhador se vê imerso na busca pelas condições de venda das mercadorias produzidas pela sua força de trabalho. Esse lugar é uma espécie de muralha construída com forma de casas-fábricas, um grande mercado onde apartamentos populares se proliferam conjuntamente à lojas que comercializam todo tipo de mercadoria, sem luz do sol, sem vias de acesso diretas ao mundo exterior, sem saída de emergência.

O Centro é a materialização do que chamamos de cotidiano alienado, sem sua elevação ou superação. Ao ser incapaz de comercializar sua mercadoria, produzida por sua força de trabalho de forma não estranhada, nos termos de Marx (2013), Sr. Cipriano tem como única alternativa passar a viver no interior do Centro, sem o trabalho ritmado pelo tempo da natureza e sem controlar o ritmo de sua própria vida. Tudo com o que se depara é o eterno lusco-fusco imposto pelas luzes artificias, tudo que lhe resta, ao ter removida sua potência ontológica criadora é morrer.

Todavia, nas últimas páginas do romance, Sr. Cipriano tem uma espécie de epifania: ao caminhar perdido entre os corredores, encontra uma escada abandonada que leva ao subsolo. Nesse lugar ermo, encontra dois esqueletos sentados, encostados um no outro, encarando uma parede rochosa onde luzes bruxuleantes projetam figuras nem vivas nem mortas, apenas contínuas em sua frequência, entonação, intensidade e conformidade. "Não é aqui que vou morrer", pensa antes de partir do Centro para sempre.

Isso não é uma mera releitura do conto da caverna de Platão mas, de certa forma, um apelo à classe trabalhadora: a recusa pelas ilusões de uma vida organizada por meio de um cotidiano que possui em sua gênese a defesa intransigente da manutenção do modo de produção. Essa recusa imediata é o início compossível para a re-invenção de práticas sociais de cooperação que sirvam à produção de outro cotidiano que atenda aos requisitos para a constituição de classe-para-si na construção de outra ordem societária.

\section{REFERÊNCIAS}

ENGELS, Friedrich.; MARX, Karl. O Manifesto do Partido Comunista. Porto Alegre: L\&PM, 2010.

FALCÃO, Maria do Carmo (org.). Conhecimento da vida cotidiana: Base necessária à prática social. In: FALCÃO, Maria do Carmo. Cotidiano: conhecimento e crítica. conhecimento e crítica. São Paulo: Cortez Editora, 1987. Cap. 1. p. 13-62.

HELLER, Agnes. O cotidiano e a história. 3. ed. São Paulo: Editora Paz e Terra, 1989.

Temporalis, Brasília (DF), ano 21, n. 41, p. 367-380, jan./jun. 2021. | ISSN 2238-1856 
LÖWY, Michel. Prefácio. In: FALCÃO, M.C.; NETTO, J.P. Cotidiano: conhecimento e crítica. 2. ed. São Paulo: Cortez, 1987.

LUKÁCS, György. L'estraniazione, Ontologia Dell'Essere Sociale, II, IV, a cura de Alberto Scarponi. Roma: Riuniti, 1976.

LUKÁCS, György. História e consciência de classe: estudos sobre a dialética marxista. São Paulo: Martins Fontes, 2003.

MARX, Karl. O Capital: volume 1 crítica da economia política. São Paulo: Boitempo, 2013. $897 \mathrm{p}$

NETTO, José Paulo. Para a crítica da vida cotidiana. In: NETTO, José Paulo. Cotidiano: conhecimento e crítica. conhecimento e crítica. São Paulo: Editora Cortez, 1987. Cap. 1987. p. 63-93.

NETTO, José Paulo. Capitalismo e Reificação. São Paulo: Livraria Editora Ciências Humanas, 1981.

MARX, Karl. Trabalho Assalariado e Capital. São Paulo: ed. Global, 1980. (coleção Bases n. 27).

MARX, Karl. Manuscritos Econômicos Filosóficos. São Paulo: Abril Cultural, 1978. (coleção Os Pensadores).

SARAMAGO, José. A Caverna. São Paulo: Companhia das Letras, 2000.

\section{Robson de Oliveira}

Doutor em Serviço Social pela Universidade Federal de Santa Catarina. Atuou como Assistente Social na área da Segurança Pública e Política Nacional de Assistência Social. Atualmente é professor do curso de Serviço Social da Universidade Federal do Paraná - Setor Litoral. 